\title{
A systematic review and meta-analysis of the prevalence of toxoplasmosis in hemodialysis patients in Iran
}

\author{
Masoud Foroutan' ', Ali Rostami'2, Hamidreza Majidiani', Seyed Mohammad Riahi ${ }^{3,4}$, \\ Sasan Khazaei', Milad Badri', Elham Yousefi ${ }^{5}$ \\ 'Department of Parasitology, Faculty of Medical Sciences, Tarbiat Modares University, Tehran, Iran; ${ }^{2}$ Infectious Diseases and Tropical Medicine \\ Research Center, Health Research Institute, Babol University of Medical Sciences, Babol, Iran; ${ }^{3}$ Department of Epidemiology, School of Public \\ Health, Shahid Beheshti University of Medical Sciences, Tehran, Iran; ${ }^{4}$ Faculty of Health, Birjand University of Medical Sciences, Birjand, Iran; \\ ${ }^{5}$ Department of Medical Parasitology and Mycology, School of Public Health, Tehran University of Medical Sciences, Tehran, Iran
}

\begin{abstract}
OBJECTIVES: Toxoplasmosis is a parasitic disease that occurs worldwide, with a wide range of complications in immunocompromised patients. This systematic review and meta-analysis was performed to evaluate the seroprevalence of Toxoplasma gondii among patients undergoing hemodialysis in Iran.

METHODS: We searched English and Persian databases for studies reporting T. gondii seroprevalence in Iranian hemodialysis patients through December 31, 2017. Inclusion and exclusion criteria were applied.

RESULTS: A total of 10 studies containing 1,865 participants (1,048 patients and 817 controls) met the eligibility criteria. Immunoglobulin G (IgG) antibodies against T. gondii were found in 58\% (95\% confidence interval [CI], 46 to 70 ) of hemodialysis patients and $40 \%$ (95\% CI, 31 to 50) of healthy controls, while immunoglobulin M (IgM) antibodies were found in $2 \%$ (95\% CI, 0 to 6$)$ of hemodialysis patients and $0 \%(95 \%$ CI, 0 to 1$)$ of healthy controls. The meta-analysis showed that hemodialysis patients were significantly more likely to be seropositive for IgG (odds ratio [OR], 2.04; 95\% CI, 1.54 to 2.70; p<0.001) and IgM (OR, 2.53; 95\% CI, 1.23 to $5.22 ; \mathrm{p}<0.001$ ) antibodies against T. gondii infection than healthy individuals.
\end{abstract}

CONCLUSIONS: The current study revealed a high prevalence of T. gondii infection in hemodialysis patients. Since hemodialysis patients are immunocompromised and T. gondii can cause serious clinical complications, we recommend that periodic screenings for T. gondii infection should be incorporated into the routine clinical care of these patients.

KEY WORDS: Toxoplasma gondii, Seroprevalence, Hemodialysis patients, Iran

\section{INTRODUCTION}

Toxoplasmosis is a cosmopolitan parasitic zoonosis caused by the well-known intracellular protist, Toxoplasma gondii [1,2]. Re-

\section{Correspondence: Ali Rostami}

Infectious Diseases and Tropical Medicine Research Center, Health Research Institute, Babol University of Medical Sciences, P.O. Box 47176-47745, Babol, Iran

E-mail: alirostami1984@gmail.com

Received: Mar 31, 2018 / Accepted: Apr 23, 2018 / Published: Apr 23, 2018

This article is available from: http://e-epih.org/

(C) This is an open-access article distributed under the terms of the Creative Commons Attribution License (http://creativecommons.org/licenses/by/4.0/), which permits unrestricted use, distribution, and reproduction in any medium, provided the original work is properly cited.

(C) 2018, Korean Society of Epidemiology cently published systematic review articles have estimated the pooled prevalence of global $T$. gondii infection in various groups of humans. For instance, prevalence ranges of 0.8 to $77.5 \%$ in pregnant women and those of childbearing age [3] and 33.0\% (95\% confidence interval [CI], 28.0 to 39.0) among apparently healthy blood donors [4] were reported from a global perspective. Furthermore, in immunocompromised persons, such as HIV/AIDS patients, cancer patients, and transplant recipients, the estimated pooled prevalence of toxoplasmosis was reported to be $42.1 \%$ (95\% CI, 34.0 to 50.2 ), $26.0 \%$ (95\% CI, 20.5 to 31.5 ), and $42.1 \%$ (95\% CI, 27.1 to 57.2 ), respectively [5].

Toxoplasmosis is frequently transmitted via congenital infections, ingesting oocyst-contaminated food or water, consuming raw or undercooked meat containing tissue cysts, and organ transplantation and blood transfusion through infected donors [6-9]. 
A wide range of ecological and behavioral risk factors, such as place of residence, geographical climate, and nutritional habits, have been implicated in parasite survival and dissemination [4,10-12]. Despite the asymptomatic and chronic nature of infection in immunocompetent individuals, toxoplasmosis may result in life-threatening outcomes in at-risk people such as pregnant women and immunocompromised individuals, including people undergoing radiation therapy, cancer patients, HIV-positive individuals, transplant recipients, multi-transfused thalassemia patients, and hemodialysis patients [13-19]. Having potential neurotropism, the main effects of the parasite are brain damage, neurological defects, and even encephalitis in immunodeficient people [13,20-24]. Unfortunately, no commercially licensed vaccine is available to prevent toxoplasmosis in humans [25,26].

The kidneys play a central role in maintaining body homeostasis via blood filtration. Without excretion, waste substrates and toxins would accumulate in the body and endanger the individual's life. Therefore, kidney transplant or hemodialysis is indispensable in individuals with renal failure [27]. According to reports, the number of people with renal failure and end-stage renal disease requiring hemodialysis has increased during the last 2 decades [28]. Patients undergoing hemodialysis are considered to be immunocompromised, particularly due to immune response dysfunctions regarding phagocytosis, chemotaxis, and the complement system [29]. Hence, these individuals are more vulnerable to opportunistic pathogens such as T. gondii [30].
Several articles have investigated the prevalence of T. gondii infection in hemodialysis patients in Iran. Herein, we present a systematic review and meta-analysis that was designed to determine the exact prevalence of the infection among this population.

\section{MATERIALS AND METHODS}

\section{Study area}

Covering a wide area in the Middle East $\left(1,648,195 \mathrm{~km}^{2}\right)$, Iran has a population of approximately 80 million (as of 2015), and is located between $25^{\circ} 3^{\prime}$ and $39^{\circ} 47^{\prime} \mathrm{N}$ and $44^{\circ} 5^{\prime}$ and $63^{\circ} 18^{\prime} \mathrm{E}$, bordering Iraq and Turkey to the west, Afghanistan and Pakistan to the east, the Persian Gulf and Oman Sea to the south, and Azerbaijan, Armenia, and Turkmenistan to the north. Except for a small region on the margin of the Caspian Sea coast with considerable annual rainfall that is covered by dense vegetation, the general climate of Iran is hot and dry, forming the Iranian plateau. It is one of the world's most mountainous countries, and its landscape is dominated by rugged mountain ranges that separate various basins and plateaus from each other. The populous western part is the most mountainous, with ranges such as the Caucasus, Zagros, and Alborz Mountains. Lower temperatures, severe winters, and heavy snowfall occur in the Zagros basin, while in the central and eastern basins there is an arid climate because of high-altitude mountain ranges in the western and northern parts. These mountain ranges are so high that rain clouds cannot reach the central and east-

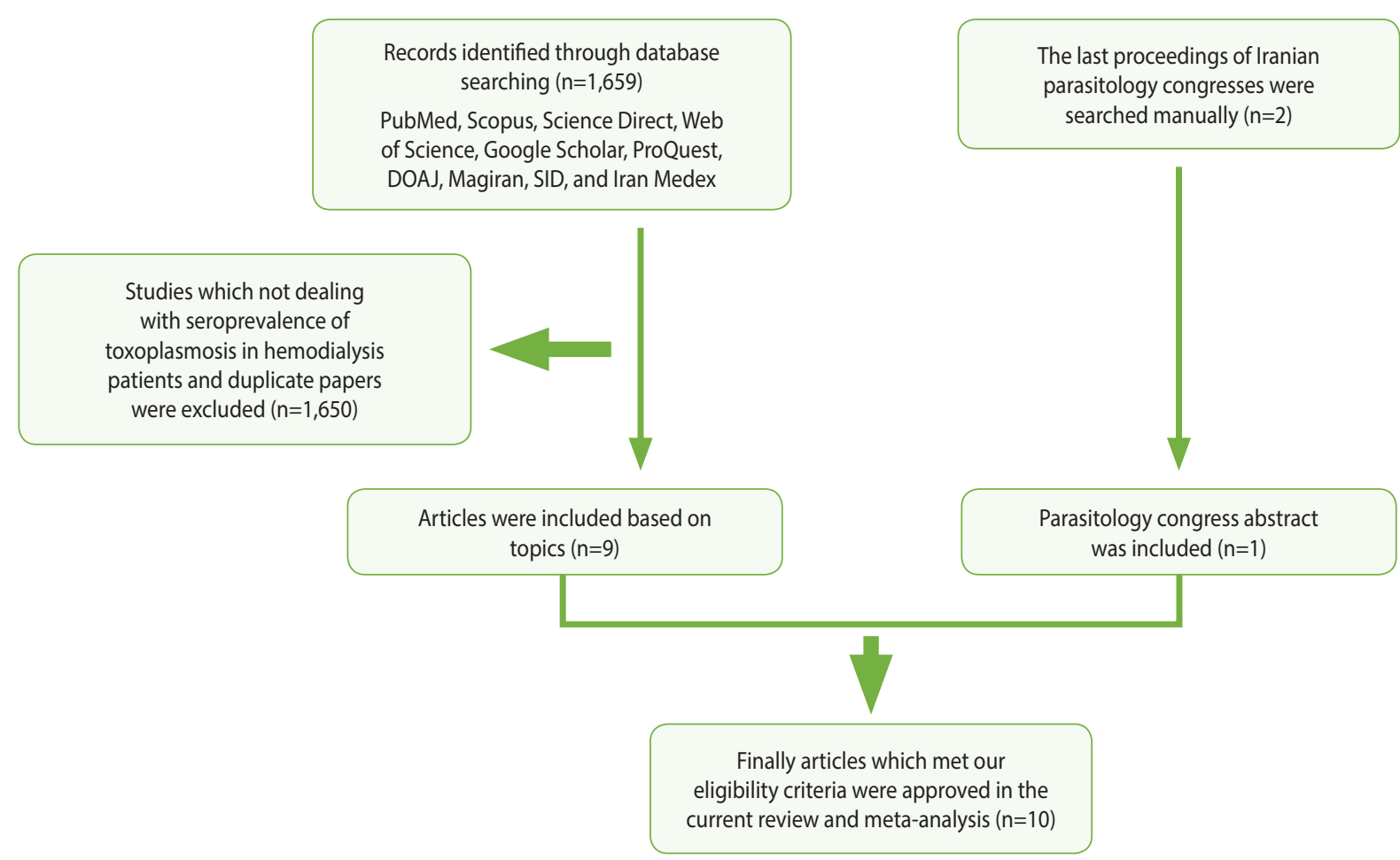

Figure 1. Flowchart describing the study design process. DOAJ, Directory of Open Access Journals; SID, Scientific Information Database. 
ern basins. Annual precipitation is $680 \mathrm{~mm}$ in the eastern part of the plain and more than $1,700 \mathrm{~mm}$ in the western part [31].

\section{Search strategy}

In order to assess the prevalence of Toxoplasma infection among hemodialysis patients in Iran, compared with healthy persons, we searched for relevant papers in 7 English-language databases (PubMed, Scopus, Science Direct, Web of Science, Google Scholar, ProQuest, and the Directory of Open Access Journals) and three Persian-language databases (Magiran, Scientific Information Database, and Iran Medex) from their inception until December 31, 2017. Additionally, the proceedings of the last 2 Iranian parasitology congresses were browsed manually (Figure 1). This systematic review was conducted using Medical Subject Heading terms, including: "Toxoplasma," "toxoplasmosis," "Toxoplasma gondii," "hemodialysis patients," "renal failure," "dialysis," "epidemiology," "prevalence," and "Iran," alone or in combination with "OR" and/ or "AND" operators.

\section{Study selection and data extraction}

The initial citations obtained during database exploration were recorded in a Word file according to their topics and abstracts. Following primary screening, potentially eligible records were selected for full-text download. The final eligibility and inclusion criteria for the downloaded full texts were appraised by 2 inde- pendent reviewers (MF and SK). The selected articles were scrutinized and discrepancies between the reviewers were addressed by discussion and consensus with a third reviewer (MB). Subsequently, an author (MF) extracted the requisite data, and the others (SK and $\mathrm{MB}$ ) rechecked them. The following inclusion criteria were applied in the current systematic review: (1) original research papers, short reports, or letters to the editor; (2) case-control studies that estimated the prevalence of toxoplasmosis in hemodialysis patients and healthy individuals; (3) studies published in English or Persian; (4) studies published online before December 31, 2017; (5) studies for which the full texts were available (abstracts from the last 2 Iranian parasitology congresses were also acceptable); and (6) studies with information on the exact total sample size and positive samples in the case and control groups. Each paper that did not meet the above-mentioned criteria was excluded. Additionally, the references of the selected papers were hand-checked to find relevant articles that were not retrieved in the database search. Ultimately, the following characteristics of each relevant study were extracted: first author, province, year of publication, sample size, seroprevalence of anti-Toxoplasma immunoglobulin $\mathrm{G}$ (IgG) and/or immunoglobulin M (IgM) antibodies in the case and control groups, the overall prevalence, matching (age, gender, or both), and age range or mean age. Moreover, details such as the diagnostic method, the cutoff value or antibody titer for serologic methods, the name of the kit that was used, results, and/or sug-

Table 1. Characteristics of the included studies

\begin{tabular}{|c|c|c|c|c|c|c|c|c|c|}
\hline \multirow{2}{*}{ Study } & \multirow{2}{*}{ Province } & \multirow{2}{*}{ Year } & \multirow{2}{*}{ Group } & \multirow{2}{*}{$\begin{array}{l}\text { Sample } \\
\text { size }\end{array}$} & \multicolumn{2}{|c|}{ Seroprevalence } & \multirow{2}{*}{$\begin{array}{l}\text { Age (range } \\
\text { or mean } \pm S D \text { ) }\end{array}$} & \multirow{2}{*}{ Matching } & \multirow{2}{*}{$\begin{array}{l}\text { Quality } \\
\text { score }\end{array}$} \\
\hline & & & & & $\lg G$ & $\lg M$ & & & \\
\hline \multirow[t]{2}{*}{ Solhjoo et al. [40] } & \multirow[t]{2}{*}{ Fars } & \multirow[t]{2}{*}{2010} & Case & 44 & $26(59.1)$ & $3(6.8)$ & $59.1-14.3$ & \multirow{2}{*}{$\begin{array}{l}\text { Age and } \\
\text { gender }\end{array}$} & \multirow[t]{2}{*}{7} \\
\hline & & & Control & 44 & $16(36.4)$ & $0(0.0)$ & $59.0-14.3$ & & \\
\hline \multirow[t]{2}{*}{ Bayani et al. [41] } & \multirow[t]{2}{*}{ Mazandaran } & \multirow[t]{2}{*}{2013} & Case & 90 & $72(80.0)$ & $0(0.0)$ & $42.5-11.5$ & \multirow[t]{2}{*}{ ND } & \multirow[t]{2}{*}{5} \\
\hline & & & Control & 50 & $38(76.0)$ & $0(0.0)$ & $34.8-10.4$ & & \\
\hline \multirow[t]{2}{*}{ Saki et al. [42] } & \multirow[t]{2}{*}{ Khuzestan } & \multirow[t]{2}{*}{2013} & Case & 280 & $82(29.3)$ & $22(7.9)$ & $16.0-80.0$ & \multirow[t]{2}{*}{ Gender } & \multirow[t]{2}{*}{6} \\
\hline & & & Control & 100 & $26(26.0)$ & $4(4.0)$ & - & & \\
\hline \multirow[t]{2}{*}{ Maraghi et al. [43] } & \multirow[t]{2}{*}{ Khuzestan } & \multirow[t]{2}{*}{2013} & Case & 150 & $61(40.7)$ & $13(8.7)$ & $21.0-87.0$ & \multirow[t]{2}{*}{ ND } & \multirow[t]{2}{*}{5} \\
\hline & & & Control & 150 & $39(26.0)$ & $0(0.0)$ & - & & \\
\hline \multirow{2}{*}{$\begin{array}{l}\text { Ebrahim Zadeh } \\
\text { et al. [44] }\end{array}$} & \multirow{2}{*}{$\begin{array}{l}\text { Sistan and } \\
\text { Baluchistan }\end{array}$} & \multirow[t]{2}{*}{2014} & Case & 37 & $21(56.7)$ & $5(13.5)$ & $17.5 \pm 4.1$ & \multirow{2}{*}{$\begin{array}{l}\text { Age and } \\
\text { gender }\end{array}$} & 7 \\
\hline & & & Control & 37 & $11(29.7)$ & $0(0.0)$ & $20.0 \pm 5.2$ & & \\
\hline Khalili et al. [45] & Chaharmahal and & 2015 & Case & 62 & $28(45.0)$ & $0(0.0)$ & - & Age & 4 \\
\hline & Bakhtiari & & Control & 100 & $33(33.0)$ & $0(0.0)$ & - & & \\
\hline Hamidi et al. [46] & East Azerbaijan & 2015 & Case & 84 & $59(70.2)$ & $0(0.0)$ & $54.3 \pm 12.6$ & Age and & 6 \\
\hline & & & Control & 50 & $34(68.0)$ & $0(0.0)$ & $55.5 \pm 8.2$ & gender & \\
\hline Rasti et al. [47] & Isfahan and Qom & 2016 & Case & 135 & $85(63.0)$ & $1(0.7)$ & $58.6 \pm 16.1$ & Age & 4 \\
\hline & & & Control & 120 & $40(33.3)$ & $0(0.0)$ & $52.8 \pm 17.0$ & & \\
\hline Rezavand et al. [48] & Tehran & 2016 & Case & 90 & $54(60.0)$ & $3(3.3)$ & $43.8 \pm 17.1$ & Age and & 5 \\
\hline & & & Control & 90 & $34(37.8)$ & $0(0.0)$ & $41.8 \pm 18.9$ & gender & \\
\hline Dorri et al. [49] & Sistan and & 2017 & Case & 76 & $56(73.7)$ & $0(0.0)$ & - & ND & 4 \\
\hline & Baluchistan & & Control & 76 & $33(43.4)$ & $0(0.0)$ & - & & \\
\hline
\end{tabular}

Values are presented as number or number (\%).

IgG, immunoglobulin G; IgM, immunoglobulin M; SD, standard deviation; ND, not described. 
gestions also were extracted. The Preferred Reporting Items for Systematic Reviews and Meta-Analyses criteria were employed to report our findings [32].

\section{Study quality assessment}

The Newcastle-Ottawa Scale was employed to assess the quality of the included papers [33]. A score with a maximum of 9 points was given for 8 items in 3 different categories, including the subject selection criteria ( $0-4$ points), the comparability of subjects (0-2 points), and exposure (0-3 points). Briefly, a study could be awarded a maximum of 1 point for each numbered item within the selection and exposure categories. Additionally, a maximum of 2 points could be given for comparability. Papers with a total score of 0-3, 4-6, and 7-9 points were considered to be of poor, moderate, and high quality, respectively [34].

\section{Meta-analysis}

The meta-analysis procedure was done as previously described [34-39]. Briefly, for each included study, the common odds ratio (OR) and respective 95\% CIs were estimated. The results of the meta-analysis were visualized as a forest plot representing the prevalence estimates and related CIs of each study, along with summary measures. Heterogeneity was also analyzed using the Cochran $\mathrm{Q}$ and $\mathrm{I}^{2}$ statistics. Furthermore, a funnel plot based on the Egger regression test was used to explore publication bias and small study effects.

\section{RESULTS}

Of the 1,659 identified articles, 10 were included, and the results from these studies were weighted (Table 1) [40-49]. One study was removed due to over-matching [50]. A flow diagram showing
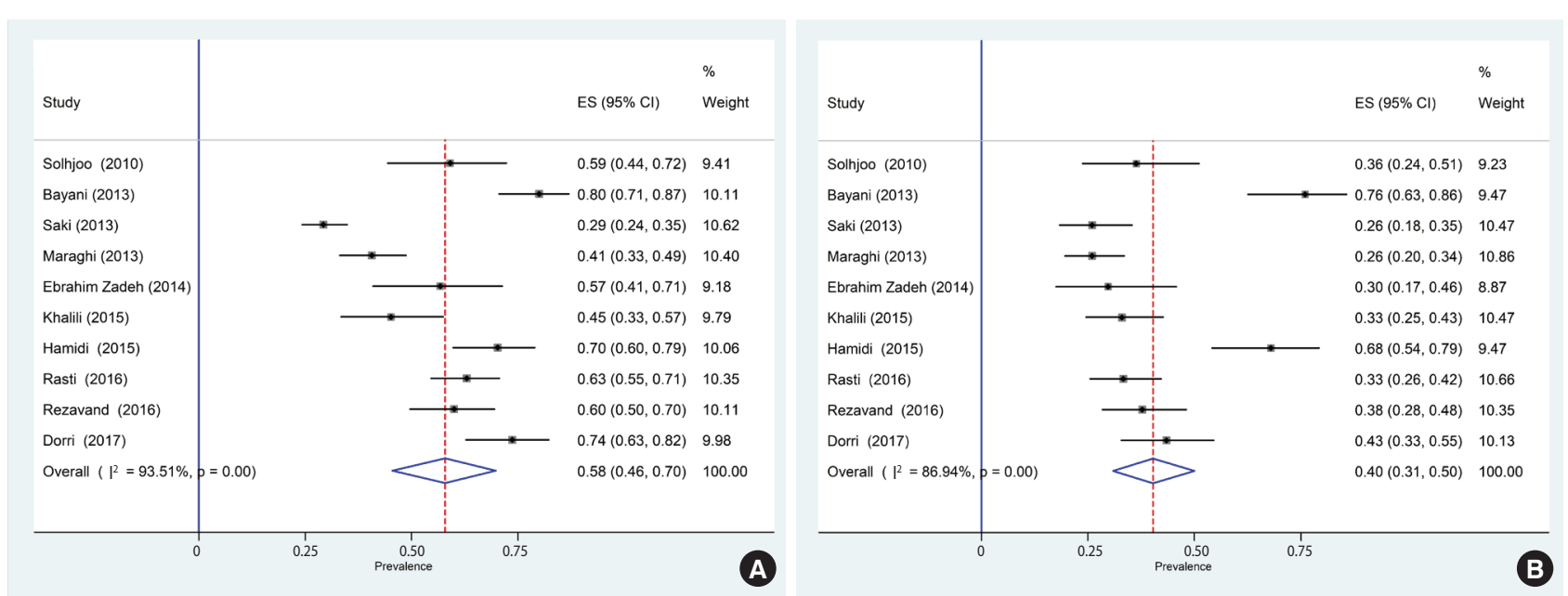

Figure 2. Forest plot diagram of the present systematic review and meta-analysis based on immunoglobulin $\mathrm{G}$ antibodies in case (A) and control (B) groups. ES, effect size; $\mathrm{Cl}$, confidence interval.
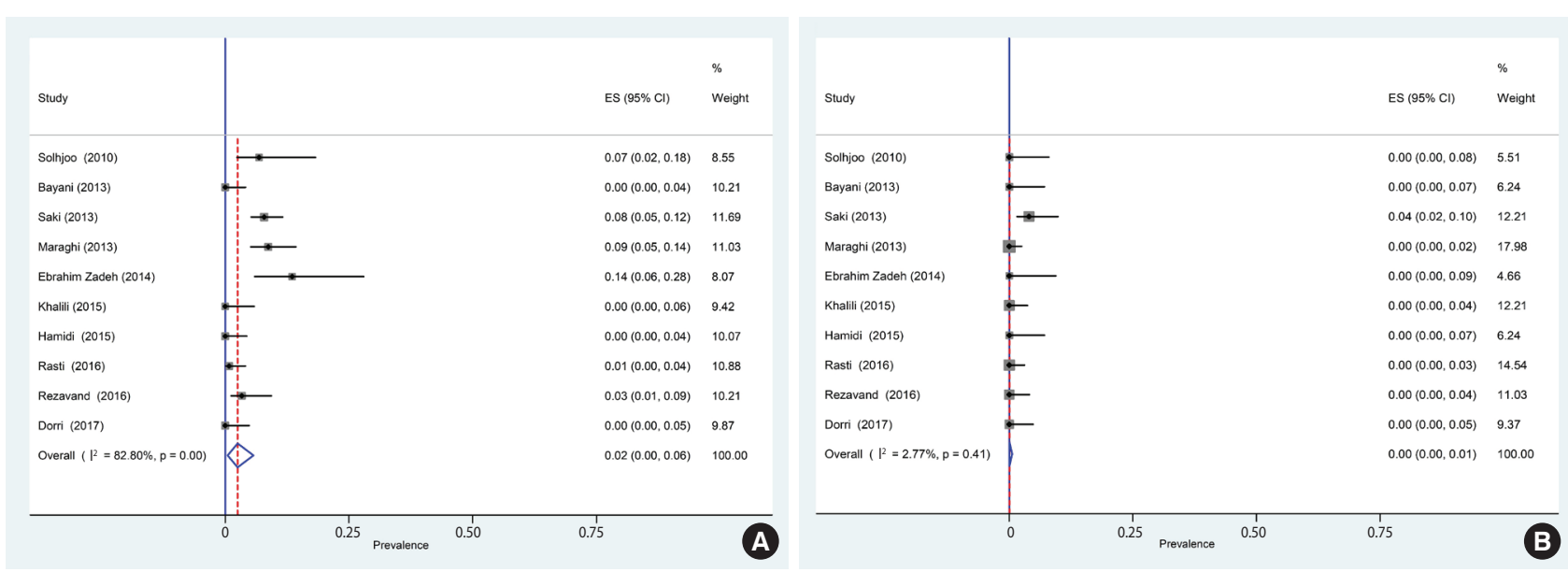

Figure 3. Forest plot diagram of the present systematic review and meta-analysis based on immunoglobulin $M$ antibodies in case ( $A$ ) and control (B) groups. ES, effect size; $\mathrm{Cl}$, confidence interval. 


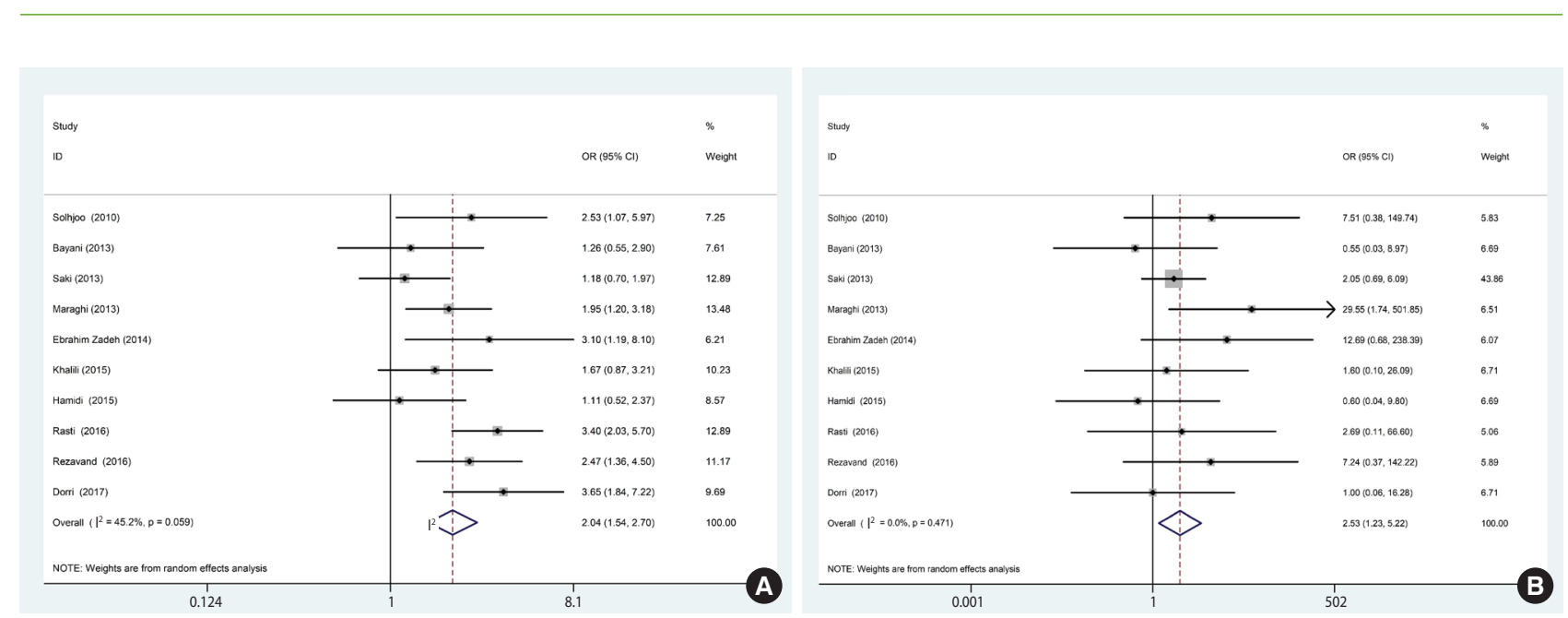

Figure 4. Forest plot of ORs related to the case (A) and control (B) groups. OR, odds ratio; $\mathrm{Cl}$, confidence interval.

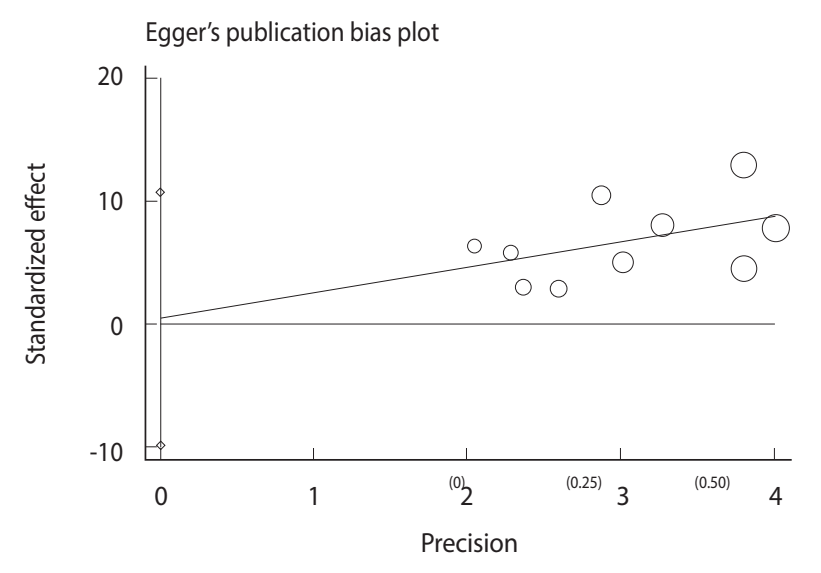

Figure 5. Egger plot for detecting publication bias. The parentheses indicate the inverse of sample size.

the study selection process is presented in Figure 1. All the included studies had a case-control design, and the number of the cases and controls was 1,048 and 817, respectively, with a total of 1,865 participants across the 10 studies included. The main characteristics and results of the included studies are shown in Table 1. IgG T. gondii antibodies were reported in 58\% (95\% CI, 46 to 70 ) of the hemodialysis patients and in $40 \%$ (95\% CI, 31 to 50) of the healthy controls (Figure 2), while IgM antibodies were found in $2 \%$ (95\% CI, 0 to 6 ) of the hemodialysis patients and $0 \%$ (95\% CI, 0 to 1 ) of the healthy controls (Figure 3). Detailed information about the studies, including the diagnostic method, cutoff value or antibody titer, and name of the kit, is presented in Supplementary Material 1.

Based on the results of the meta-analysis, patients undergoing hemodialysis were significantly more likely to be seropositive for $\operatorname{IgG}(\mathrm{OR}, 2.04$; 95\% CI, 1.54 to 2.70 ; $\mathrm{p}<0.001)$ and IgM (OR, 2.53; $95 \%$ CI, 1.23 to $5.22 ; \mathrm{p}<0.001)$ antibodies against $T$. gondii infection than healthy individuals (Figure 4). The heterogeneity among the studies for $\operatorname{IgG}\left(\chi^{2}=16.42 ; \mathrm{I}^{2}=45.2 \% ; 95 \% \mathrm{CI}, 0\right.$ to 74$)$ and $\operatorname{IgM}\left(\chi^{2}=8.64 ; I^{2}=0.0 \% ; 95 \% \mathrm{CI}, 0\right.$ to 62$)$ antibodies was acceptable. To identify publication bias, we used Egger plots (Figure 5). According to the symmetry assumption, no significant publication bias was found in studies presenting results for the $\operatorname{IgG}(p=0.92)$ and $\operatorname{IgM}(\mathrm{p}=0.33)$ antibodies.

\section{DISCUSSION}

Elevated levels of blood urea in patients suffering from chronic kidney disease could lead to dysfunction of immunological factors such as polymorphonuclear leukocytes, nitric oxide, and platelets [30], thereby weakening the immune system and increasing the risk of infection, which is the cause of $40 \%$ of deaths in these patients [51]. Dialysis is essential to remove waste materials, excess water, and urea from the blood, and therefore plays a vital role in promoting survival and improving the quality of life of these patients [29]. Therefore, screening for opportunistic infections such as toxoplasmosis, identifying the potential risk factors for such infections, and ensuring early treatment in such patients would be useful.

The present meta-analysis assessed the seroprevalence of T. gondii infection in hemodialysis patients in Iran. The results demonstrated a relatively high prevalence (58\%) of $T$. gondii infection in hemodialysis patients, which was significantly higher than was observed in healthy controls. The prevalence reported here generally agrees with other studies of Iranian immunocompromised individuals, including transplant recipients (55\%) and HIV/AIDS patients (50\%) [52]. However, this rate is significantly higher than the mean (39\%) seroprevalence of T. gondii infection previously reported in the general population and cancer patients in Iran $(45 \%)$ [11,52]. Moreover, the prevalence we observed in hemodialysis patients is in accordance with the reports of Yazar et al. [53] from Turkey (56.0\%), which borders Iran, Aufy et al. [54] from Egypt (56.0\%), and Alvarado-Esquivel et al. [55] from Mexico 


\section{(56.7\%).}

Regarding acute infections, our results indicated that $2.0 \%$ of Iranian patients undergoing hemodialysis were seropositive for IgM. This result is consistent with the rate reported by Yazar et al. [53] in Turkey (1.7\%), but lower than that reported by Aufy et al. [54] in Egypt (16.7\%). Moreover, among the included studies, only $3[42,47,48]$ applied molecular methods (polymerase chain reaction) to detect $T$. gondii infection. In all those studies, active infection (circulating DNA) was only observed in hemodialysis patients, whereas no controls showed positive results $[42,47,48]$. This result indicates that hemodialysis patients were more susceptible to acquire T. gondii infection. This trend could have been due to the inability of these patients to ensure appropriate personal and food hygiene. Considering the immune system dysfunction in these patients, acute or active infection could result to life-threatening complications, such as encephalitis.

The comprehensive literature search, rigorous methodology, duplicated data extraction and quality assessment by 2 independent reviewers, clear inclusion and exclusion criteria, and the absence of publication bias are strengths of this meta-analysis. Nonetheless, there are some limitations of our study that are due to the nature of the studies that were included. In case-control studies, selecting the controls is an important pitfall. Some of the included studies did not apply matching for case and controls, and in the majority of the included studies, the healthy controls were drawn from an undefined setting. Moreover, the majority of the studies included in this meta-analysis did not provide data about the duration of dialysis; therefore, we were unable to assess the effect of this important factor on the prevalence of infection. Another issue could be variation in the sensitivity and specificity of enzyme-linked immunosorbent assay kits and the different cutoff values that were used to detect IgG and IgM antibodies. Furthermore, most of the included studies did not evaluate risk factors, which is an important issue regarding the acquisition of $T$. gondii infection in immunocompromised patients. It has been well demonstrated that suppression of the host immune response is an important risk factor for the reactivation of chronic infections. Other important risk factors for T. gondii infection are intake of sporulated oocysts from contaminated water or unwashed fruit and vegetables, keeping cats indoors as pets, and the consumption of raw or undercooked meat containing T. gondii tissue cysts $[1,4,10,12]$. The geographical area is also an important factor associated with the prevalence of T. gondii infection [12]. In Iran, the highest prevalence of T. gondii infection was observed in northern areas. In the present metaanalysis, the study by Bayani et al. [41] that was performed in Mazandaran Province (north Iran) reported the highest prevalence of T. gondii infection in cases and controls.

\section{Recommendations}

Some recommendations for the better management and treatment of hemodialysis patients and subsequent studies are given below: (1) We suggest that periodic screenings for T. gondii infection should be incorporated into the routine clinical care of he- modialysis patients; (2) Measures to prevent the acquisition of $T$. gondii infection, such as eating well-cooked meat and well-cleaned vegetables, are also recommended; (3) More studies are needed to further understand the prevalence of T. gondii infection and the impact thereof on the health of hemodialysis patients in regions where studies of this subject have not been carried out; and (4) We recommended that a standard questionnaire be designed for a more comprehensive assessment of related risk factors, including place of residence, gender, the duration of hemodialysis, education level, blood group, occupation, and history of immune suppression.

\section{CONCLUSION}

The results of this study revealed that acute and chronic T. gondii infections were more frequent in hemodialysis patients than in healthy controls. Since patients undergoing hemodialysis are immunocompromised, T. gondii infections, especially in the acute phase, could cause serious clinical complications.

\section{ACKNOWLEDGEMENTS}

The authors would like to thank all the staff members of the Departments of Parasitology of Tarbiat Modares and Babol Universities, Iran.

\section{CONFLICT OF INTEREST}

The authors have no conflicts of interest to declare for this study.

\section{SUPPLYMENTARY MATERIALS}

Supplementary Material 1: Table S1 is available at http://www.eepih.org/.

\section{ORCID}

Masoud Foroutan: http://orcid.org/0000-0002-8661-7217; Ali Rostami: http://orcid.org/0000-0002-1358-1321; Hamidreza Majidiani: $h t t p: / / o r c i d . o r g / 0000-0001-5568-1366$; Seyed Mohammad Riahi: http://orcid.org/0000-0002-3184-2126; Sasan Khazaei: http: //orcid.org/0000-0003-3366-464X; Milad Badri: http://orcid.org/ 0000-0003-4086-9782; Elham Yousefi: https://orcid.org/0000-00023990-7561

\section{REFERENCES}

1. Foroutan M, Dalvand S, Daryani A, Ahmadpour E, Majidiani H, Khademvatan S, et al. Rolling up the pieces of a puzzle: a systematic review and meta-analysis of the prevalence of toxoplasmosis in Iran. Alex J Med 2017. doi: https://doi.org/10.1016/j.ajme.2017. 06.003 .

2. Shiadeh MN, Niyyati M, Fallahi S, Rostami A. Human parasitic 
protozoan infection to infertility: a systematic review. Parasitol Res 2016;115:469-477.

3. Pappas G, Roussos N, Falagas ME. Toxoplasmosis snapshots: global status of Toxoplasma gondii seroprevalence and implications for pregnancy and congenital toxoplasmosis. Int J Parasitol 2009; 39:1385-1394.

4. Foroutan-Rad M, Majidiani H, Dalvand S, Daryani A, Kooti W, Saki J, et al. Toxoplasmosis in blood donors: a systematic review and meta-analysis. Transfus Med Rev 2016;30:116-122.

5. Wang ZD, Liu HH, Ma ZX, Ma HY, Li ZY, Yang ZB, et al. Toxoplasma gondii infection in immunocompromised patients: a systematic review and meta-analysis. Front Microbiol 2017;8:389.

6. Rostami A, Riahi SM, Fakhri Y, Saber V, Hanifehpour H, Valizadeh S, et al. The global seroprevalence of Toxoplasma gondii among wild boars: a systematic review and meta-analysis. Vet Parasitol 2017;244:12-20.

7. Foroutan M, Majidiani $\mathrm{H}$. Toxoplasma gondii: are there any implications for routine blood screening? Int J Infect 2018;5:e62886.

8. Khademvatan S, Foroutan M, Hazrati-Tappeh K, Dalvand S, Khalkhali H, Masoumifard S, et al. Toxoplasmosis in rodents: a systematic review and meta-analysis in Iran. J Infect Public Health 2017;10:487-493.

9. Soltani S, Khademvatan S, Saki J, Shahbazian H. Detection of toxoplasmosis in renal transplant recipients by ELISA and PCR methods in Ahvaz, south-west of Iran. Jundishapur J Microbiol 2013;6:e7642.

10. Rostami A, Seyyedtabaei SJ, Aghamolaie S, Behniafar H, Lasjerdi $\mathrm{Z}$, Abdolrasouli A, et al. Seroprevalence and risk factors associated with Toxoplasma gondii infection among rural communities in Northern Iran. Rev Inst Med Trop Sao Paulo 2016;58:70.

11. Daryani A, Sarvi S, Aarabi M, Mizani A, Ahmadpour E, Shokri A, et al. Seroprevalence of Toxoplasma gondii in the Iranian general population: a systematic review and meta-analysis. Acta Trop 2014;137:185-194.

12. Foroutan-Rad M, Khademvatan S, Majidiani H, Aryamand S, Rahim F, Malehi AS. Seroprevalence of Toxoplasma gondii in the Iranian pregnant women: a systematic review and meta-analysis. Acta Trop 2016;158:160-169.

13. Rostami A, Keshavarz H, Shojaee S, Mohebali M, Meamar AR. Frequency of Toxoplasma gondii in HIV positive patients from West of Iran by ELISA and PCR. Iran J Parasitol 2014;9:474-481.

14. Nourollahpour Shiadeh M, Rostami A, Pearce BD, Gholipourmalekabadi M, Newport DJ, Danesh M, et al. The correlation between Toxoplasma gondii infection and prenatal depression in pregnant women. Eur J Clin Microbiol Infect Dis 2016;35:18291835.

15. Yousefi E, Foroutan M, Salehi R, Khademvatan S. Detection of acute and chronic toxoplasmosis amongst multi-transfused thalassemia patients in southwest of Iran. J Acute Dis 2017;6:120-125.

16. Khademvatan S, Saki J, Yousefi E, Abdizadeh R. Detection and genotyping of Toxoplasma gondii strains isolated from birds in the southwest of Iran. Br Poult Sci 2013;54:76-80.

17. Gharavi MJ, Jalali S, Khademvatan S, Heydari S. Detection of
IgM and IgG anti-Toxoplasma antibodies in renal transplant recipients using ELFA, ELISA and ISAGA methods: comparison of pre- and post-transplantation status. Ann Trop Med Parasitol 2011;105:367-371.

18. Saki J, Shafieenia S, Foroutan-Rad M. Seroprevalence of toxoplasmosis in diabetic pregnant women in southwestern of Iran. J Parasit Dis 2016;40:1586-1589.

19. Fallahi S, Rostami A, Nourollahpour Shiadeh M, Behniafar H, Paktinat S. An updated literature review on maternal-fetal and reproductive disorders of Toxoplasma gondii infection. J Gynecol Obstet Hum Reprod 2018;47:133-140.

20. Fallahi S, Rostami A, Birjandi M, Zebardast N, Kheirandish F, Spotin A. Parkinson's disease and Toxoplasma gondii infection: sero-molecular assess the possible link among patients. Acta Trop 2017;173:97-101.

21. Khademvatan S, Saki J, Khajeddin N, Izadi-Mazidi M, Beladi R, Shafiee B, et al. Toxoplasma gondii exposure and the risk of schizophrenia. Jundishapur J Microbiol 2014;7:e12776.

22. Khademvatan S, Khajeddin N, Izadi S, Yousefi E. Investigation of anti-Toxocara and anti-Toxoplasma antibodies in patients with schizophrenia disorder. Schizophr Res Treatment 2014;2014:230349.

23. Khademvatan S, Khajeddin N, Saki J, Izadi-Mazidi S. Effect of toxoplasmosis on personality profiles of Iranian men and women. S Afr J Sci 2013;109:0017.

24. Khademvatan S, Riahi F, Izadi-Mazidi M, Khajeddin N, Yousefi E. Toxoplasma gondii exposure and the risk of attention deficit hyperactivity disorder in children and adolescents. Pediatr Infect Dis J 2018. doi: https://doi.org/10.1097/INF.0000000000001985.

25. Foroutan M, Ghaffarifar F. Calcium-dependent protein kinases are potential targets for Toxoplasma gondii vaccine. Clin Exp Vaccine Res 2018;7:24-36.

26. Foroutan M, Ghaffarifar F, Sharifi Z, Dalimi A, Pirestani M. Bioinformatics analysis of ROP8 protein to improve vaccine design against Toxoplasma gondii. Infect Genet Evol 2018;62:193-204.

27. Stevens LA, Coresh J, Greene T, Levey AS. Assessing kidney function--measured and estimated glomerular filtration rate. N Engl J Med 2006;354:2473-2483.

28. Kurella Tamura M. Incidence, management, and outcomes of end-stage renal disease in the elderly. Curr Opin Nephrol Hypertens 2009;18:252-257.

29. Omrani VF, Fallahi Sh, Rostami A, Siyadatpanah A, Barzgarpour G, Mehravar S, et al. Prevalence of intestinal parasite infections and associated clinical symptoms among patients with end-stage renal disease undergoing hemodialysis. Infection 2015;43:537544.

30. Kato S, Chmielewski M, Honda H, Pecoits-Filho R, Matsuo S, Yuzawa $Y$, et al. Aspects of immune dysfunction in end-stage renal disease. Clin J Am Soc Nephrol 2008;3:1526-1533.

31. Khalkhali HR, Foroutan M, Khademvatan S, Majidiani H, Aryamand S, Khezri P, et al. Prevalence of cystic echinococcosis in Iran: a systematic review and meta-analysis. J Helminthol 2018; 92:260-268.

32. Moher D, Shamseer L, Clarke M, Ghersi D, Liberati A, Petticrew 
$\mathrm{M}$, et al. Preferred reporting items for systematic review and meta-analysis protocols (PRISMA-P) 2015 statement. Syst Rev 2015; 4:1.

33. Stang A. Critical evaluation of the Newcastle-Ottawa scale for the assessment of the quality of nonrandomized studies in meta-analyses. Eur J Epidemiol 2010;25:603-605.

34. Aghaei S, Riahi SM, Rostami A, Mohammadzadeh I, Javanian M, Tohidi E, et al. Toxocara spp. infection and risk of childhood asthma: a systematic review and meta-analysis. Acta Trop 2018;182: 298-304.

35. Majidiani H, Dalvand S, Daryani A, Galvan-Ramirez ML, Forou$\tan$-Rad M. Is chronic toxoplasmosis a risk factor for diabetes mellitus? A systematic review and meta-analysis of case-control studies. Braz J Infect Dis 2016;20:605-609.

36. Khademvatan S, Majidiani H, Foroutan M, Hazrati Tappeh K, Aryamand S, Khalkhali HR. Echinococcus granulosus genotypes in Iran: a systematic review. J Helminthol 2018:1-8.

37. Maleki B, Khorshidi A, Gorgipour M, Mirzapour A, Majidiani H, Foroutan M. Prevalence of Toxocara spp. eggs in soil of public areas in Iran: a systematic review and meta-analysis. Alex J Med 2018;54:97-101.

38. Foroutan M, Khademvatan S, Majidiani H, Khalkhali H, Hedayati-Rad F, Khashaveh S, et al. Prevalence of Leishmania species in rodents: a systematic review and meta-analysis in Iran. Acta Trop 2017;172:164-172.

39. Foroutan M, Dalvand S, Khademvatan S, Majidiani H, Khalkhali $\mathrm{H}$, Masoumifard S, et al. A systematic review and meta-analysis of the prevalence of Leishmania infection in blood donors. Transfus Apher Sci 2017;56:544-551.

40. Solhjoo K, Jahromi AS, Parnian-Rad A. Anti-Toxoplasma gondii antibodies in haemodialysis patients. Am J Infec Dis 2010;6:1317.

41. Bayani M, Mostafazadeh A, Oliaee F, Kalantari N. The prevalence of Toxoplasma gondii in hemodialysis patients. Iran Red Crescent Med J 2013;15:e5225.

42. Saki J, Khademvatan S, Soltani S, Shahbazian H. Detection of toxoplasmosis in patients with end-stage renal disease by enzymelinked immunosorbent assay and polymerase chain reaction methods. Parasitol Res 2013;112:163-168.

43. Maraghi S, Yadyad MJ, Sheikhi M, Shamakhteh F, Latifi SM. Study the anti-Toxoplasma antibodies (IgG and IgM) in hemodialysis patients of Abadan and Khoramshahr cities Southwest Iran in 2011 using ELISA. Jundishapur J Microbiol 2013;6:e7113.

44. Ebrahim Zadeh A, Bamedi T, Etemadi S, Shahrakipour M, Saryazdipour K. Toxoplasmosis as a complication of transfusion in hemodialysis patients. Iran J Ped Hematol Oncol 2014;4:22-25.

45. Khalili B, Mortezaei S, Fazeli M. The comparison of anti-Toxoplasma antibody (IGM, IgG) in hemodialysed patients and those undergoing chemoterapy with healthy blood donor, shahr-E-kord, 1392. Iran J Parasitol 2015;10(Suppl 1):311.

46. Hamidi F, Etemadi J, Ghabouli Mehrabani N, Mahami-Oskouei M, Motavalli R, Ardalan M. Comparison of Toxoplasma gondii seropositivity in hemodialysis and peritoneal dialysis patients. J Coast Life Med 2015;3:621-622.

47. Rasti S, Hassanzadeh M, Soliemani A, Hooshyar H, Mousavi SG, Nikoueinejad H, et al. Serological and molecular survey of toxoplasmosis in renal transplant recipients and hemodialysis patients in Kashan and Qom regions, central Iran. Ren Fail 2016;38:970973.

48. Rezavand B, Poornaki AM, Mokhtari KR, Mohammad A, Andalibian A, Abdi J. Identification and determination of the prevalence of Toxoplasma gondii in patients with chronic renal failure by ELISA and PCR. Asian Pac J Trop Dis 2016;6:347-349.

49. Dorri M, Dabirzadeh M, Maroufi Y, Afshari M, Chokamy MB. Prevalence of anti-Toxoplasma IgG and IgM in hemodialysis patients comparing to healthy individuals in Sistan area, Iran. J Nephropharmacol 2017;6:106-109.

50. Seyyedpour SH, Afshar P, Barzegarnejad A, Kalhori S, Agah R. Evaluation of anti-Toxoplasma gondii antibodies in hemodialysis patients with chronic kidney disease in Sari, Iran. Nephrourol Mon 2016;8:e40182.

51. de Jager DJ, Grootendorst DC, Jager KJ, van Dijk PC, Tomas LM, Ansell D, et al. Cardiovascular and noncardiovascular mortality among patients starting dialysis. JAMA 2009;302:1782-1789.

52. Ahmadpour E, Daryani A, Sharif M, Sarvi S, Aarabi M, Mizani A, et al. Toxoplasmosis in immunocompromised patients in Iran: a systematic review and meta-analysis. J Infect Dev Ctries 2014;8: 1503-1510.

53. Yazar S, Demirtaş F, Yalçin S, Yaman O, Tokgöz B, Utaş C, et al. Anti-Toxoplasma gondii antibodies in haemodialysis patients with chronic renal failure. Yonsei Med J 2003;44:288-292.

54. Aufy SM, Mahgoub AM, Saadi MG, Adel Elmallawany M. Serological detection of Toxoplasma gondii in chronic renal failure patients and renal transplant recipients. J Egypt Soc Parasitol 2009; 39:943-950.

55. Alvarado-Esquivel C, Liesenfeld O, Torres-Castorena A, EstradaMartínez S, Urbina-Alvarez JD, Ramos-de la Rocha M, et al. Seroepidemiology of Toxoplasma gondii infection in patients with vision and hearing impairments, cancer, HIV, or undergoing hemodialysis in Durango, Mexico. J Parasitol 2010;96:505-508. 